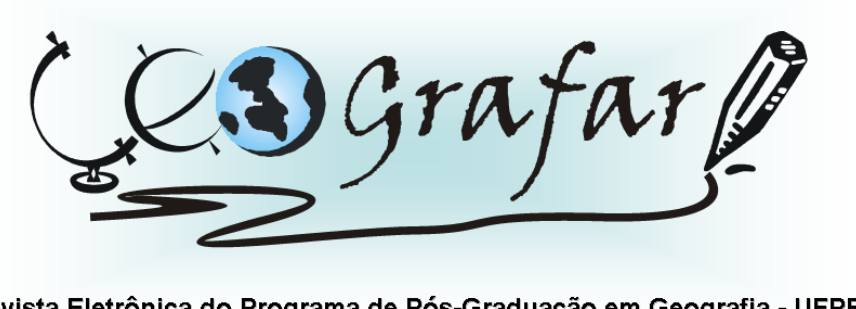

Revista Eletrônica do Programa de Pós-Graduação em Geografia - UFPR

\title{
POR UMA TIPOLOGIA DAS COMUNIDADES TRADICIONAIS BRASILEIRAS
}

\author{
DOUGLAS GRZEBIELUKA ${ }^{1}$
}

\begin{abstract}
RESUMO
No Brasil, em muitas áreas florestais vivem populações conhecidas como tradicionais, as quais desenvolvem um modo singular de viver, pois estão em constante interdependência com a natureza, desenvolvendo sistemas de manejo sustentáveis. O presente artigo tem por objetivo propor a tipologia de algumas Comunidades Tradicionais, bem como traçar características que permitem singularizá-las, identificando as principais comunidades que vivem tradicionalmente no território brasileiro.
\end{abstract}

Palavras-chaves: Território brasileiro, Comunidades Tradicionais, Cultura.

\section{FOR A TYPE OF THE BRAZILIAN TRADITIONAL COMMUNITIES}

\begin{abstract}
In Brazil, in many forest áreas known as traditional living populations, which developed a unique way of living, as they are in constant interdependence with nature, developing sustainable management systems. This article aims to propose some type of traditional communities, as well as features that allow singles to trace them, identifying the main traditional communities living in Brazil.
\end{abstract}

Key-words: Brazilian territory, traditional communities, culture.

\footnotetext{
${ }^{1}$ Mestre em Gestão do Território/Universidade Estadual de Ponta Grossa, Professor da SEED-PR, e.mail: douglasgebeluka@bol.com.br.
} 


\section{INTRODUÇÃO}

Diante da conjuntura sócio-espacial que o meio rural brasileiro vivencia e se organiza, faz-se necessário alguns conhecimentos básicos sobre como se estruturam as comunidades neste meio e quais as perspectivas de futuro das mesmas perante a sociedade. Com essa visão, pretende-se abrir novos horizonte em relação ao discurso que permeia o campo relativo à dinâmica sócio-espacial de comunidades tradicionais; partindo do pressuposto que estas comunidades tradicionais exercem um papel fundamental em relação à conservação de valores culturais, históricos, sociais e de conservação da biodiversidade.

No Brasil, assistimos recentemente a um reconhecimento de uma série de povos e comunidades tradicionais, hoje reunidos em uma Comissão oficial que os representa junto ao governo federal e que, com este, traçam as diretrizes políticas nesta esfera. Neste contexto o presente artigo apresenta a tipologia destas comunidades, buscando uma diferenciação entre elas.

Nesse contexto, o presente artigo tem por objetivo propor uma tipologia das Comunidades Tradicionais, bem como traçar características que permitem singularizá-las, identificando as principais comunidades que vivem tradicionalmente no território brasileiro.

$\mathrm{O}$ artigo encontra-se estruturado da seguinte forma: inicia-se o trabalho com a conceituação de Comunidades Tradicionais, destacando suas principais características e os valores culturais que preservam. Segue apresentando a tipologia de algumas das principais Comunidades Tradicionais existentes no território brasileiro demonstrando suas particularidades no modo de viver.

Como metodologia de trabalho optou-se por revisão bibliográfica referente ao assunto. Diante de leitura sistemática da bibliografia procurou-se destacar os principais pontos pertinentes ao assunto, como forma de facilitar a compreensão e posterior escrita. 


\section{CONCEITUANDO COMUNIDADES TRADICIONAIS}

No Brasil, em muitas áreas florestais, vivem populações conhecidas como tradicionais, as quais desenvolvem um modo singular de viver, pois estão em constante interdependência com a natureza, desenvolvendo sistemas de manejo sustentáveis. São populações que mantém uma relação direta com o ambiente natural onde se encontram inseridas; se utilizam deste ambiente de forma a garantir a utilização de recursos por sucessivas gerações. As atividades que desenvolvem são de baixo impacto ambiental e de baixa articulação com o mercado, sendo em sua maioria atividades para a própria subsistência. (DIEGUES, 2004, p. 87).

As comunidades tradicionais são culturalmente diferenciadas das demais formas de organização social e, portanto, se reconhecem como tais; possuem formas próprias de organização social, ocupam e usam o território e recursos naturais para sua "reprodução cultural, social, religiosa, ancestral e econômica"; para tanto, utilizam-se de inovações e práticas geradas e transmitidas pela tradição de geração para geração. (DECRETO № 6.040, [...], 2007).

Estas comunidades desenvolveram formas particulares de manejo dos recursos naturais, que não visam diretamente ao lucro, mas à reprodução cultural e social, além de percepções e representações em relação ao mundo natural, marcadas pela idéia de associação com a natureza e a dependência de seus ciclos. Culturas tradicionais, nessa perspectiva, são aquelas associadas à pequena produção. Assim, comunidades tradicionais são grupos coletivos humanos que possuem um modo de vida distinto da nossa sociedade padronizada pela indústria cultural, não produzindo os danos ambientais que as comunidades urbanas produzem; sendo a auto-identificação, o "reconhecer-se como pertencente," uma das mais importantes características para o reconhecimento destas comunidades enquanto povos tradicionais. (DIEGUES, 2004, p. 87-88).

Essas comunidades apresentam distinções em relação ao modo seu de viver, possuem uma cultura rica em costumes e crenças que são construídas no decorrer dos anos e transmitidas de geração para geração.

Longo foi o processo de reconhecimento destas comunidades enquanto "Povos Tradicionais"; uma luta que está presente desde a Constituição Brasileira de 
1988, onde sobretudo os Índios, mas também os quilombolas, foram reconhecidos e ganharam o reconhecimento da sua "organização social, costumes, línguas, crenças e tradições" (CONSTITUIÇÃO BRASILEIRA, [...], 1988). Desde então, somente no ano de 2004, temos o Decreto Presidencial que organiza a "Comissão Nacional de Desenvolvimento Sustentável das Comunidades Tradicionais"; sendo este revogado pelo Decreto de 13 de julho de 2006, o qual altera a denominação, competência e composição da referida comissão. Somente no ano de 2007 que entra em vigor o Decreto Presidencial $N^{\circ}$ 6.040, o qual institui a "Política Nacional de Desenvolvimento Sustentável dos Povos e Comunidades Tradicionais", reconhecendo-Ihes e lhes dando a devida atenção e assistência.

Com o reconhecimento dessas populações considera-se que muitas pessoas fazem parte de comunidades tradicionais:

Cerca de 5 milhões de pessoas no Brasil fazem parte de comunidades tradicionais. Elas ocupam um quarto do território brasileiro e representam segmentos diversos - desde os mais conhecidos, como indígenas e quilombolas, até os de menor expressão, como os faxinais (que vivem no Paraná, plantam mate e criam porcos) e os pomeranos (etnia européia que vive no Espírito Santo). Grande parte desses povos mora em lugares distantes e não tem acesso às políticas governamentais, o que os torna mais suscetíveis à pobreza. (BEDINELLI, 2009, p.01).

A utilização dos termos populações, povos e comunidades tradicionais, mesmo em documentos ou na própria legislação, demonstra que é preciso ainda estabelecer uma série de questionamentos no que se refere à categorização desses grupos e também que se definam critérios que assegurem os direitos dessa população. A inclusão social, que é uma ação de combate à exclusão, tem por finalidade oferecer aos mais necessitados oportunidades de participarem de um sistema que beneficie a todos, inclusive aqueles que se encontram longe dos centros urbanos.

As comunidades tradicionais, por viverem em áreas afastadas, buscam obter meios de sobrevivência desenvolvendo seus próprios conhecimentos em relação à natureza e o seu próprio modo de viver. 
Com isolamento relativo, essas populações desenvolveram modos de vida particulares que envolvem grande dependência dos ciclos naturais, conhecimento profundo dos ciclos biológicos e dos recursos naturais, tecnologias patrimoniais, simbologias, mitos e até uma linguagem específica, com sotaques e inúmeras palavras de origem indígena e negra. (DIEGUES, 2004, p.14).

Esse conjunto de costumes, comportamentos, valores, língua e religião são construídos conforme a diferença de identidade de um povo, que requer respeito aos seus direitos culturais. É preciso que se estabeleçam entendimentos sobre o universo que as comunidades tradicionais abarcam, bem como a certeza de uma definição que seja abrangente e inclusiva garantindo a essas populações seus direitos. Essas comunidades prestam um serviço público na defesa da biodiversidade, por isso merecem o reconhecimento de seus préstimos ao meio ambiente.

Conforme Zimmermann (2009, p.01):

Desde o início de seu mandato, o Governo Lula se propôs a diversificar o âmbito de beneficiários de suas políticas públicas. A instituição, pelo Decreto ํo 6.040/2007, da Política Nacional de Desenvolvimento Sustentável dos Povos e Comunidades Tradicionais (PNPCT) se deu nesse sentido. Essa política entende que, num país tão diverso em sua composição étnica e cultural, é um grande desafio estabelecer e implementar políticas públicas para promoção do bemestar social dessas populações que, muitas vezes, encontram-se na invisibilidade, sendo socialmente excluídas por pressões econômicas, fundiárias ou por processos discriminatórios.

Em suas ações o Governo Federal deveria melhorar os efeitos dos projetos e programas públicos para essas comunidades, principalmente na elaboração dessa Política Nacional de Desenvolvimento Sustentável dos Povos e Comunidades Tradicionais, e assim desenvolver ações que dêem sustentação para que estas permaneçam no seu território.

Para Bedinelli:

As ações deverão abranger, entre outros pontos, políticas de melhoria do acesso a escolas e postos de saúde; projetos que diminuam o impacto de grandes empreendimentos nos territórios tradicionais; políticas de inclusão social e de reconhecimento da cidadania (como a redução do sub-registro civil); e o incentivo a atividades relacionadas a pesca, extrativismo de ervas e plantas, 
lavoura e outros produtos comuns a essas populações. (BEDINELLI, 2009, p.01).

De acordo com a Política Nacional de Desenvolvimento Sustentável de Povos e Comunidades Tradicionais (2006), a questão primordial é o acesso a terra ou ao território; assegurar esse direito significa manter vivos na memória os acontecimentos e fatos históricos do grupo. E também manter as práticas sociais, os sistemas de manejo dos recursos, os sistemas produtivos, os modos de produção e distribuição da produção.

Diegues aponta diferenciações entre estruturas do saber que interferem no cotidiano das comunidades tradicionais:

Configura-se, nesse caso, o confronto de dois saberes: o tradicional e o científico-moderno. De um lado, está o saber acumulado das populações tradicionais sobre os ciclos naturais, a reprodução e migração da fauna, a influência da lua nas atividades de corte de madeira, da pesca, sobre os sistemas de manejo dos recursos naturais, as proibições do exercício de atividades em certas áreas ou períodos do ano, tendo em vista a preservação das espécies. De outro lado, está o conhecimento científico, oriundo das ciências exatas que não apenas desconhece, mas despreza o conhecimento tradicionalmente acumulado. (DIEGUES, 2004, p.69).

Entende-se que essas comunidades caracterizam-se pela dependência dos recursos naturais com os quais constroem o seu modo de viver. As comunidades tradicionais se utilizam de conhecimentos adquiridos através do tempo, e também se destacam pelas inovações e práticas criadas dentro da própria comunidade e transmitidas para as novas gerações. Mas com o processo de desapropriação dessas comunidades tradicionais, muitos jovens perdem 0 encanto pela permanência em seu local de origem dado o seu relacionamento com outros povos.

Para Diegues e Viana:

A maioria dos sistemas de manejo desenvolvidos e empregados por comunidades tradicionais contempla, de forma empírica, vários dos aspectos que favorecem a manutenção da estrutura das populações naturais sob extrativismo. Entretanto, na maior parte dos casos, tal conhecimento vem se perdendo por causa do desinteresse das gerações mais jovens e, principalmente, por causa dos processos de aculturação a que são submetidas tais comunidades. (DIEGUES; VIANA, 2004, p.99). 
O desenvolvimento, a tecnologia e o progresso que garantem o bem estar também são causas do agravamento das degradações e destruições da natureza. $O$ crescimento desordenado da economia origina uma crise na civilização que questiona a racionalidade dos sistemas sociais e culturais.

Podemos destacar as seguintes características das comunidades tradicionais, segundo Diegues (2004, p. 87-88), as quais são:

- Dependência da relação de simbiose entre a natureza, os ciclos e os recursos naturais renováveis com os quais se constrói um modo de vida;

- Conhecimento aprofundado da natureza e de seus ciclos, que se reflete na elaboração de estratégias de uso e de manejo dos recursos naturais. Esse conhecimento é transferido de geração em geração por via oral;

- Noção de território ou espaço onde o grupo social se reproduz econômica e socialmente;

- Moradia e ocupação do território por várias gerações, ainda que alguns membros individuais possam ter-se deslocado para os centros urbanos e voltado para a terra de seus antepassados;

- Importância das atividades de subsistência, ainda que a produção de mercadorias possa estar mais ou menos desenvolvida, o que implica uma relação com o mercado;

- Reduzida acumulação de capital;

- Importância dada à unidade familiar, doméstica ou comunal e às relações de parentesco ou compadrio para o exercício das atividades econômicas, sociais e culturais;

- Importância das simbologias, mitos e rituais associados à caça, pesca e atividades extrativistas;

- A tecnologia utilizada, que é relativamente simples, de impacto limitado sobre o meio ambiente. Há uma reduzida divisão técnica e social do trabalho, sobressaindo o artesanal, cujo produtor (e sua família) domina todo o processo de trabalho até o produto final;

- Fraco poder político, que em geral reside com os grupos de poder dos centros urbanos; e

- Auto-identificação ou identificação pelos outros de se pertencer a uma cultura distinta das outras.

As atitudes ambientais que possibilitam uma melhor qualidade de vida se encontram nos sistemas agrários tradicionais, ou seja, nas comunidades tradicionais, e estas parecem preencher requisitos de auto-sustentabilidade.

Nelas ainda se trabalha de forma coletiva, pelo menos em determinados âmbitos de atuação. Mesmo com toda política de 
modernização agrária - sistematização, funcionalização e individualização da agricultura - este sistema resiste às forças da racionalidade do capitalismo moderno." (LÖWEN SAHR, 2007, p. 208).

Para uma comunidade tradicional ser reconhecida ela precisa trabalhar sustentavelmente, ou seja, o uso dos recursos naturais precisa ser equilibrado e voltado para a melhoria da qualidade de vida da geração atual e das próximas que virão. "O envolvimento sustentável deve buscar reverter o distanciamento do homem em relação à natureza. Ao envolver as sociedades com o ecossistema local, são fortalecidos os vínculos econômicos, sociais, espirituais, culturais e ecológicos." (DIEGUES; VIANA, 2004 p.26).

No Brasil, assistimos recentemente a um reconhecimento de uma série de povos e comunidades tradicionais, hoje reunidos em uma Comissão oficial que os representa junto ao governo federal e que, com este, traçam as diretrizes políticas nesta esfera. No item seguinte apresenta-se uma tipologia destas comunidades, buscando uma diferenciação entre elas.

\section{POR UMA TIPOLOGIA DAS COMUNIDADES TRADICIONAIS}

No Brasil, temos representando o amplo espectro das comunidades tradicionais: os Caiçaras, os Quilombolas, os Ribeirinhos, os Seringueiros e Castanheiros, as Quebradeiras de Coco, as populações de Fundo de Pasto, os Ciganos e os Faxinalenses. Traçamos a seguir alguns elementos que permitem singularizá-las.

O processo de ocupação e povoamento do Brasil seguiu a trajetória litoral/interior. Num primeiro momento a população concentrava-se nas áreas litorâneas do nosso país; mas depois de algum tempo, os desbravadores, resolveram ultrapassar a barreira da Serra do Mar. Mesmo depois da conquista do interior, a Serra do Mar continuou sendo uma barreira de comunicação entre a população do interior e a do litoral. Os Caiçaras permaneceram residindo predominantemente no litoral do Paraná, São Paulo e Rio de Janeiro, garantindo certo isolamento. 
Descendente da miscigenação entre os portugueses e índios, "O gênero de vida caiçara combina agricultura de subsistência, baseada na mandioca e na pesca" (ADAMS, 2000, p. 147). A pesca é uma prática comum entre os homens e o peixe é o principal alimento deste povo. Ocorrem, muitas vezes, as trocas de peixes por outros produtos necessários alimentação, principalmente de alimentos produzidos nas roças. Porcos e galinhas fazem parte das criações domésticas dos Caiçaras. Homens e mulheres possuem papel definidos dentro das comunidades. As mulheres são as responsáveis por afazeres da vida doméstica e por pequenas roças, enquanto os homens são responsáveis por infra-estrutura, manutenção e sustento (ADAMS, 2000, p. 149).

Apesar do isolamento que existe entre os integrantes das comunidades Caiçaras, este povo pratica trocas de produtos e também se organizam em mutirões, sendo que a divisão dos produtos ocorre de forma igualitária. Os ranchos, em meio à mata e rentes a orla marítima, são simples e sem cercas, sendo que todas as propriedades são interligadas por carreiros. Adams (2000, p. 150) relata que "o sertão era o espaço do trabalho, onde se encontravam as roças, os bananais e a floresta, de onde se retirava a lenha, ervas medicinais e onde se caçava."

O povo Caiçara é assim, grande detentor dos conhecimentos naturais do ambiente onde habita, possuindo uma cultura e modo de viver particular. Nos últimos anos, com a criação de Áreas de Proteção Ambiental e com as novas tecnologias, estes se resumiram a pescadores que resistem as pressões externas que lhes são impostas pela sociedade. (ADAMS, 2000).

Desvalorização, preconceito, maus tratos e humilhações são termos na lembrança que acompanham a trajetória dos negros em nosso país desde os tempos do descobrimento. Em meio a preconceitos e discriminações, entretanto, as populações Quilombolas vêm demonstrando seu exemplo de autonomia, resistência e de auto-identificação com a raça negra. Atualmente são "[...] reconhecidas como símbolo de uma identidade, de uma cultura e, sobretudo, de um modelo de luta e militância negra." (ARRUTI, 1997, p. 22).

Os quilombos surgem da necessidade de organização em comunidades de escravos fugitivos de grandes fazendas ou de mão de obra ociosa devido às inovações tecnológicas que surgem no campo. Com estas inovações, a mão de obra 
escrava torna-se incompatível com os novos meios de produção. A revolta dos escravos, aliada à intensa exploração, são motivos que levam muitos escravos a fugir e a partir de então se organizam em comunidades onde se desenvolveram de forma autônoma, comunidades estas historicamente conhecidas por quilombos. (JUNIOR; SILVA; COSTA, 2008, p. 14).

O isolamento dos Quilombolas proporcionou aos mesmos, o desenvolvimento de uma cultura original. As comunidades - em meio à mata -descobrem formas específicas de exploração da floresta, forçadas pelo isolamento a elas conferido. Nestas comunidades homens e mulheres possuem papéis distintos em relação à vida diária; as mulheres são responsáveis por tarefas domésticas e cuidados com os filhos, enquanto o homem busca em meio à mata e em pequenas roças o sustento para a família.

Segundo Junior; Silva e Costa:

Os quilombos ficavam em lugares de difícil acesso, escondidos nas matas, selvas ou montanhas, formando aldeias, onde os seus habitantes, os quilombolas, dedicavam-se à economia de subsistência e, às vezes, ao comércio. Alguns deles tentaram reproduzir a organização social africana, inclusive com a escolha de reis tribais (JUNIOR; SILVA; COSTA, 2008, p. 14).

A identidade étnica é à base de uma comunidade Quilombola na atualidade, para que esta expresse seu potencial de organização e de sua ação política. (ARRUTI, 1997; JÚNIOR; SILVA; COSTA, 2008). Assim, as comunidades Quilombolas apresentam traços culturais relativos a um período histórico que deve ser preservado e que merece seu devido respeito perante toda a sociedade. A busca por uma significância histórica e por seu reconhecimento são as marcas da luta quilombola por uma vida com mais justiça, dignidade e igualdade.

Os Ribeirinhos são "[...] trabalhadores e trabalhadoras que residem proximidades dos rios e, que há muito caracterizam-se por ter como principal atividade de subsistência a pesca." (NEVES, 2008, p. 01).

Estas comunidades caracterizam-se pela diversificação nas atividades produtivas, as quais giram em torno da cultura dos conhecimentos adquiridos sobre a natureza e seu funcionamento, garantindo a sobrevivência de acordo com necessidades e principalmente com o que o meio Ihes oferece. Para Guarim (2000, 
p. 09) estas comunidades "[...] se envolvem, freqüentemente, com muito fervor, em atividades religiosas comunitárias, organizadas ou pela Igreja Católica ou pelas Igrejas Protestantes Fundamentalistas".

Os Ribeirinhos desempenham um papel fundamental na preservação da biodiversidade local onde estão inseridos; muitas vezes mantendo uma relação de dependência ou até mesmo de troca entre eles e o ambiente. $O$ profundo conhecimento dos ciclos da natureza facilita a elaboração de técnicas de manejo dos recursos naturais.

Vítimas da seca de algumas regiões do nordeste, os seringueiros começam a chegar ao estado do Acre a partir de 1877, com a expectativa de encontrar melhores condições de vida. De início, devido ao modo rústico de trabalhar, estes homens eram conhecidos por "brabos"; desenvolviam seu trabalho diariamente na floresta, pois os mesmos não tinham condições para desenvolverem, nem mesmo uma agricultura de subsistência. Em 1913 os seringais da Amazônia entram em crise devido ao preço do produto no mercado mundial. A queda nos preços fez com que muitos seringueiros passassem a dedicar-se as atividades agrícolas e também pecuárias; desenvolvendo uma agricultura familiar baseada em múltiplos usos dos recursos da floresta (PORTO-GONÇALVES, 2001).

Os seringueiros guardam consigo o conhecimento adquirido ao longo dos anos vividos em meio à mata; de um ecossistema extremamente diversificado e complexo em meio à floresta Amazônica, "[...] desenvolveram todo um saber, todo um conhecimento na sua convivência com os ecossistemas amazônicos que, sem dúvida, constitui um enorme acervo cultural." (PORTO-GONÇALVES, 2001, p. 22).

As atividades nos seringais e de coleta da castanha estão correlacionadas uma a outra. Estas atividades funcionam como complementares. Dependendo da estação do ano, os Seringueiros migram para atividades da coleta da castanha tornando-se Castanheiros. "O extrativismo da borracha sempre esteve ligado ao da castanha que é praticado nas mesmas áreas; o primeiro na época menos chuvosa (maio a novembro) e o segundo, no período mais chuvoso (dezembro a março)". (MURRIETA; RUEDA, 1995, p. 04).

Tendo por base o trabalho de Santos, podemos considerar as seguintes características das comunidades de seringueiros: 
[...] se percebem como comunidade, discutem e conhecem a vida em todo o rio, estabelecem laços de compadrio, se solidarizam. Com freqüência, percebem que a existência da reserva extrativa só faz sentido na medida que todos estiverem espalhados e vigilantes para não sofrerem invasões. (SANTOS, 2002, p. 27).

Murrieta e Rueda (1995), bem como Porto-Gonçalves (2001), destacam também o grande conhecimento empírico destes, conhecimento este derivado da vivência na floresta: as práticas medicinais, bem como a fabricação de remédios; a domesticação de animais; a culinária com sabores típicos da floresta; o conhecimento de propriedades medicinais, aromáticas e cosméticas de plantas existentes em meio à mata; a realização de mutirões; e também a religiosidade aliada ao ambiente da floresta, gerando mitos onde tudo se relaciona com tudo em uma visão holística.

Após o término da Segunda Guerra Mundial, os Seringueiros passam a ser donos ou posseiros de parcelas de terra antes pertencentes ao seu patrão. Com a queda dos preços do produto, estes senhores deixaram suas terras e seguiram em busca de novas atividades, abandonando os seringais.

Atualmente, os seringueiros sofrem pressões externas, devido ao fato da exploração madeireira e das forças políticas atuantes na região, mas resistem agindo em defesa e pela sobrevivência da floresta. Este povo vive de forma simples em meio à floresta; habitam casas rústicas cobertas de palha, praticam a caça e a agricultura em reduzida escala em prol de seu sustento. Apesar desta situação precária, muitos seringueiros preferem continuar em meio aos seringais.

Santos aponta que:

[...] no seringal o rendimento do trabalho pode ser menor, mas não falta peixe e farinha, não tendo, portanto, gastos com energia e água, além de poderem fazer suas próprias casas; ao menos a sobrevivência da família fica garantida e os filhos não passam fome. (SANTOS, 2002, p. 16).

Muitos seringueiros, após a baixa na produção da borracha e nas exportações, migraram para outras regiões da Amazônia ou até mesmo para outras regiões do Brasil. Mas "[...] muitos que permaneceram nos seringais reforçando seus laços com a terra, por meio de uma agricultura de subsistência, associada ao 
extrativismo da borracha e da castanha, do comércio de peles e madeira [...]" (PORTO-GONÇALVES, 2001, p. 37), conseguiram um bom nível de subsistência aliando atividades como a pesca, a caça, o cultivo de frutas silvestres e extrativismo vegetal as atividades tradicionais. A alimentação é complementada com peixes, sendo que muitas famílias sobrevivem da pesca artesanal, praticada de forma simples em pequena escala, diferentemente da atividade pesqueira comercial.

As Quebradeiras de Coco tem uma história de resistência e de organização. Trata-se de mulheres pobres da região do semi-árido maranhense. Ali desde cedo elas aprendem este ofício que é passado de mãe para filha. No Maranhão, cerca de 300 mil pessoas vivem da extração do coco do babaçu, $90 \%$ são mulheres. Mas a história dessas quebradeiras muda de acordo com o município em que vivem, já que nem todos adotaram a Lei do Babaçu Livre, que permite a extração mesmo em terras privadas. (MATOS, 2005).

Diante dos inúmeros problemas que a população nordestina enfrenta, devido à seca, agricultores do Sertão - conhecidos como moradores dos Fundos de Pasto reúnem-se em comunidades a fim de garantir novas formas de sustento e reprodução social, sendo que o Estado e a Igreja desempenham um papel fundamental neste processo de integração. (SABOURIN, 2001; SILVA et al., 2000).

As áreas de Fundo de Pasto no Brasil são consideradas as terras de livre pastoreio no sertão nordestino, assim, estas comunidades caracterizam-se pela existência de quatro tipos de espaços distintos: "o espaço pioneiro, o espaço de produção diversificada, a bacia de produção e o espaço marginalizado" (SILVA et al., 2000, p. 09). O espaço pioneiro é também chamado de fundo de pasto. Estas comunidades muitas vezes resultam da partilha de terras entre famílias, ou até mesmo de famílias que possuem afinidades, sendo a religião a principal característica a ser considerada. (SABOURIN, 2001; SILVA et al., 2000). "O Fundo de Pasto, permanece como propriedade indivisível da família estendida ou da 'comunidade'. (SILVA et al., 2000, p. 07).

Baseados no processo da reciprocidade é que esses grupos nordestinos se organizam e dão vida as suas comunidades; este tipo de organização se reflete em mutirões e processos de ajuda mútua. A realização de mutirões nas comunidades Fundo de Pasto contam com a presença de todos os integrantes da família e 
também da comunidade. Ao final do mutirão como forma de recompensa e também como incentivo à participação, realiza-se uma festa com rezas em agradecimento, muita comida e bebida. Mulheres e crianças são responsáveis pela realização de tarefas mais leves, enquanto os homens ficam com o trabalho pesado. Os mutirões são realizados para atender diversos fins, individuais ou de interesse coletivo. (SABOURIN, 2001, p. 04).

Segundo Sabourin:

A integração ao mercado e à sociedade global (administração, escola, igrejas, serviços técnicos) levaram a sociedade rural nordestina, dos sítios e das comunidades, a dotar-se de novas estruturas de representação e de cooperação, sem portanto, abandonar (pelo menos completamente) os valores e formas de organização camponesa fundadas pela reciprocidade. (SABOURIN, 2001, p. 05).

Mesmo com todas as mudanças ocorridas no campo social, econômico e também tecnológico, percebe-se que as comunidades de Fundo de Pasto mantém seus vínculos com o passado, os quais se tornam indissolúveis frentes a estas transformações, proporcionando a todos os membros da comunidade um desenvolvimento econômico igualitário.

Os ciganos foram os primeiros negociadores de escravos no Brasil Colônia, em um período que engloba em torno de 300 anos de negociação na época da escravidão. Considera-se, todavia, que "[...] os ciganos foram inexpressivos no tempo, espaço e quantidade, por absoluta falta de recursos financeiros, falta de liberdade e coerção mesmo, para não realizarem este comércio". (PAIVA, 2006, p. 05). Estes homens sofrem com o preconceito de características que lhe foram atribuídas ao longo de sua trajetória. Acredita-se que o povo cigano é originário da Índia e que se espalharam por todas as partes do mundo; "[...] a mais fundamental característica dos ciganos, é a de não possuir território delimitado reconhecido por outros povos; daí são considerados, pela ONU, nação sem território. Os ciganos simplesmente consideram o mundo seu território." (PAIVA, 2009, p. 05).

Paiva (2009) nos coloca que a comunidade cigana preserva valores que são mantidos vivos até os dias atuais. Destaca algumas características culturais pertencentes a este grupo, como: a) nomadismo, os membros da comunidade 
cigana procuram meios de sobrevivência de acordo com este espírito de liberdade; b) musicalidade e dança aliada a alegria e aos sentimentos; também aliados com relação à natureza; c) Direito Consuetudinário, onde prevalece a ordem dos mais velhos; d) casamento étnico como forma de valorizar a cultura e preservar valores; e) família extensa, englobando todos os parentes, sendo o elo de ligação com o restante da comunidade; f) amor às crianças, sendo educadas de forma que jamais precise um pai bater em seu filho; g) respeito aos mais velhos, sendo seus conselhos ouvidos e seguidos por todos; h) morte e luto, respeito aos mortos, sendo respeitados definitivamente para o resto de suas vidas; i) religiosidade baseada no culto em Deus (Devel) e na entidade do mal (Beng); costumam se adaptar as religiões predominantes nos países onde vivem; j) negócios, hoje em dia entre os membros da comunidade já existem pessoas formadas e que ocupam grandes cargos; no geral são ótimos comerciantes; k) língua Ágrafa, com dialetos próprios dentro de cada grupo.

Este grupo encontra-se concentrado no Rio de Janeiro, Bahia, Pernambuco, Minas Gerais e em alguns Estados da região Sul do Brasil. Os ciganos fazem parte de um grupo de cultura bastante diversificada, onde dentro da comunidade cigana encontramos ramificações de grupos com dialetos próprios e características singulares, sendo o romani ${ }^{2}$ o dialeto fundamental das comunidades ciganas. Possuidores de um passado rico de conhecimento adquiridos no decorrer de suas andanças resultados da vida nômade que vive. (PAIVA, 2009). Atualmente alguns ciganos continuam nesta vida nômade e outros vivem de forma semi-nômade.

No Estado de Santa Catarina, em Garuva, Joinville, Araquari e Itapoá e no Estado do Paraná em Guaratuba vivem as Cipozeiras e os Cipozeiros. Estas pessoas lutam por seu reconhecimento e pela manutenção de seus direitos. Até o momento contabiliza-se em torno de 1.200 integrantes que abrangem as Comunidades de Cipozeiras e Cipozeiros, porém, acredita-se que este número seja bem maior, em torno de 10.000 membros.

De acordo Ladik e Souza (2010, p.[...]) estas comunidades possuem "[...] uma identidade coletiva que se constitui predominantemente pelo acesso aos recursos

\footnotetext{
2 ROMANI: dialeto que derivou do velho sânscrito e vem ao longo de mil anos recebendo contribuições de todas as línguas por onde este povo passa algum tempo.
} 
naturais presentes na Mata Atlântica, ou seja, do Cipó-Imbé, Liaça, Palmito, Veludo, Xaxim, e outras espécies vegetais". O trabalho nestas comunidades esta voltado principalmente ao corte do Cipó-Imbé, com o qual produzem artigos artesanais que contribui significativamente para a obtenção de renda. Destacam-se entre os saberes tradicionais das Cipozeiras e Cipozeiros técnicas como a pesca e o roçado. (HERNASKI, 2009; LADIK; SOUZA, 2010).

No decorrer dos diferentes ciclos econômicos vivenciados na dinâmica sócioespacial brasileira surge na região de matas mistas do Paraná ou Mata com Araucária, um sistema agrosilvipastoril típico, que vivencia seu auge com a fase de exploração da erva-mate - o Sistema Faxinal.

Este Sistema define-se como sendo uma forma harmônica de utilização de áreas interligadas e cobertas por vegetações de Floresta com Araucárias; estas áreas permitem o uso de criadouros extensivos e comuns, ou seja, coletivos ou comunitários, bem como, extração de erva mate e de algumas espécies vegetais para consumo, como fonte de energia ou outras atividades de interesse comunitário para a geração de renda (CHANG, 1988a).

As comunidades inseridas neste modo de vida a partir de 2005 se reconheceram como tradicionais, inserindo-se na luta das demais populações e comunidades tradicionais do Brasil, distribuídas em diferentes biomas e com características especificas. A partir deste momento elas passam a ser denominadas comunidades de Faxinais ou comunidades faxinalenses.

Löwen Sahr destaca as seguintes características como sendo próprias das comunidades faxinalenses:

- Associam a pecuária, a agricultura e o extrativismo, num sistema singular;

- Partilham o chão, ou seja, as terras do criadouro são de uso comum;

- Criam de forma coletiva animais de pequeno e grande porte soltos e misturados;

- Praticam uma agricultura de subsistência com instrumentos tradicionais (enxada, tração animal);

- Partilham as sementes, criações, produtos através de trocas;

- Praticam uma cultura de extrativismo (erva-mate, madeira, pinhão);

- Desenvolvem uma atividade agroflorestal e prezam pela conservação da biodiversidade;

- Possuem uma forte convivência e integração com o meio ambiente; 
- Possuem uma história e uma cultura própria;

- Preservam e respeitam as suas tradições, os seus costumes e a sua cultura (festas, rezas);

- Praticam uma religiosidade popular;

- Apresentam uma vida comunitária, solidária e de união;

- Integram em sua convivência famílias com terra e famílias que não tem terra;

- Possuem normas e fazem acordos baseados na cultura e tradição;

- Trabalham de forma solidária em Multirões/Puxirões;

- Partilham os bens, os serviços e os conhecimentos;

- Lutam pela sobrevivência;

- Possuem alegria de viver, amor a natureza, liberdade, esperança, confiança e união.

(LÖWEN SAHR, 2005, p. 57).

A harmonia na utilização de espaços coletivos para a criação de animais em ambiente da Floresta com Araucária é a característica que diferencia os Faxinais das outras comunidades tradicionais. Este princípio é resultante da relação confiança entre os faxinalenses. Está harmonia coletiva também está presente na realização de algumas tarefas na forma de organização de mutirões (NERONE, 2000 , p. 126). Os mutirões são práticas comuns entre os faxinalenses, organizados de acordo com as necessidades individuais de moradores das comunidades; garantem um trabalho coletivo de forma que beneficiam todos os envolvidos e garantem a manutenção do princípio da reciprocidade entre os moradores.

No Paraná, constata-se que existiram pelo menos 152 comunidades de Faxinais. Atualmente apenas 44 destas são consideradas remanescentes, ou seja, mantêm sua organização social típica; 56 estão desativadas, ou seja, preservam apenas a paisagem de Faxinal em Matas com Araucária; e 52 estão extintas, ou seja, perderam totalmente suas características originais. (MARQUES, 2004, p. 15; LÖWEN SAHR; CUNHA, 2005, p. 95). Estas comunidades encontram-se "localizadas em 16 municípios do Paraná pertencentes ao bioma da Mata de Araucária. As áreas de uso comum totalizam 15.915 hectares. Os povos de faxinal agregam um total de 3.454 famílias." (LÖWEN SAHR, 2005, p. 56).

Em relação à localização territorial dos Faxinais, pode-se dizer que a maioria foi fruto das condições naturais da região Centro-Sul do Paraná. Esta é uma região que possui em abundância as Matas Mistas com Araucárias; estas matas são ricas em erva-mate, principal produto que sustentou e configurou a estrutura dos faxinais. Também há indícios desse Sistema nos estados de Santa Catarina e Rio Grande do 
Sul, porém, a sua permanência tornou-se impossível devido ao alto grau de modernização agrícola da região, a qual recebeu altos investimentos no setor. (CHANG, 1988b, p. 49).

\section{CONSIDERAÇÕES FINAIS}

A atual visibilidade das Comunidades Tradicionais se deu através das constantes negociações entre seus membros e representantes do poder público em prol de seus direitos e do seu reconhecimento. Esta luta ganha força a partir do envolvimento de membros da sociedade civil, organizações não governamentais (ong's) e pesquisadores preocupados com a manutenção e permanência destas comunidades.

As comunidades tradicionais mostram-se como "diques" de contenção, frente às inúmeras transformações ocorridas no espaço rural. Sua forma de organização, a relação entre seus membros, a relação com a natureza e o modo peculiar como estas pessoas vivem, fortalecem os laços de companheirismo no interior da comunidade e lhes ajudam a manter-se afastados das grandes transformações tecnológicas que a sociedade presencia. Suas técnicas são construídas ao longo do tempo e transmitidas de geração para geração, tornando-se um legado histórico. $O$ impacto ambiental causado por estas comunidades é baixíssimo, visto que os moradores destes locais sabem e entendem a interdependência homem/natureza.

Percebe-se que as Comunidades Tradicionais possuem um modo de viver simples e adequado as condições físicas e econômicas que a região onde estão inseridas lhes oferece. A interdependência de seus membros com o meio ambiente faz com que estas comunidades sejam importantes fontes de preservação ambiental.

As Comunidades Tradicionais representam importante patrimônio histórico/cultural, rico em representações e caracterizado pelo modo simples de viver. A relação homem/natureza busca o equilíbrio. Neste sentido, vale ressaltar que estas comunidades necessitam de ações para que elas não passem a constar apenas na memória da sociedade. 


\section{REFERÊNCIAS}

ADAMS, C. As populações Caiçaras e o mito do bom selvagem: a necessidade de uma nova abordagem interdisciplinar. Revista de Antropologia. São Paulo, USP, V. 43, no 1, 145-182, 2000.

ARRUTI, J. M. A. A emergência dos remanescentes: notas para o diálogo entre indígenas e quilombolas. Mana - Estudos de Antropologia Social. Rio de Janeiro, UFRJ, V. 3, no 2, 7-38, 1997.

BEDINELLI, T. Povos tradicionais terão políticas adaptadas. Disponível em: $<$ http://www.amazonia.org.br/noticias/print.cfm?id=234456> Acesso em: 30 de maio de 2009.

BRASIL. CONSTITUIÇÃO DA REPÚBLICA FEDERATIVA DO BRASIL (1988). Brasília, DF: Presidência da República, 1988. Disponível em: $<$ http://www.planalto.gov.br/ccivil 03/Constituicao/Constitui\%E7ao Compilado.htm\#a dct>. Acesso em: 15 de junho de 2009.

DECRETO DE 27 DE DEZEMBRO DE 2004. Brasília, DF: Presidência da República, 2004. Disponível em: <http://www.planalto.gov.br/CCivil_03/_Ato20042006/2004/Dnn/Dnn10408.htm>. Acesso em: 15 de junho de 2009.

DECRETO DE 13 DE JULHO DE 2006. Brasília, DF: Presidência da República, 2006. Disponível em: <https://www.planalto.gov.br/ccivil_03/_Ato20042006/2006/Dnn/Dnn10884.htm>. Acesso em: 15 de junho de 2009.

. DECRETO № 6.040, DE 7 DE FEVEREIRO DE 2007. Brasília, DF: Presidência da República, $2007 . \quad$ Disponível em: $<$ https://www.planalto.gov.br/ccivil 03/ ato2007-2010/2007/decreto/d6040.htm>. Acesso em: 15 de junho de 2009.

CHANG, M. Y. Faxinais no Paraná. Informe de Pesquisa. Curitiba, v. 12, ํo 80, março, 1988a. 20.p.

Sistema Faxinal: Uma forma de organização Camponesa em desagregação no centro-sul do Paraná. Londrina: IAPAR, 1988b. 124p. (Boletim técnico, 22).

DIEGUES, A. C. S. 0 mito moderno da natureza intocada. $4^{a}$ ed. São Paulo: HUCITEC: NUPAUB: USP, 2004. 169 p.

DIEGUES, A. C. S.; VIANA, V. M. (Orgs.). Comunidades Tradicionais e Manejo dos Recursos Naturais da Mata Atlântica. $2^{\underline{a}}$ ed. São Paulo: HUCITEC: NUPAUB: CEC, 2004. 273 p. 
GZEBIELUKA, D.; LÖWEN SAHR, C. L. Comunidades de Faxinal e suas dinâmicas sócio-espaciais: da formação à desagregação de uma tradição no Município de Tibagi (PR) - um estudo sobre o Faxinal dos Empoçados. Revista Geografar. Curitiba, v.4, no.1, p.34-58, jan./jun. 2009.

GUARIM, V. L. Sustentabilidade Ambiental em Comunidades Ribeirinhas Tradicionais. In: III SIMPÓSIO SOBRE RECURSOS NATURAIS E SÓCIOECONOMICOS DO PANTANAL: OS DESAFIOS DO NOVO MILÊNIO, 1, 2000, Corumbá - MS. ANAIS ... Corumbá: FAPEMAT, 2000. p. 01 - 33

JÚNIOR, J. G.; SILVA, G. L. da; COSTA, P. A. B. Paraná Negro. UFPR/PROEC, 2008. 104 p.

HERNASKI, M. Movimento interestadual das Cipozeiras - MIC. Disponível em: $<$ http://www.fundodireitoshumanos.org.br/viewConteudoOut.nofilter?pager.offset=20\&catTipo=PRO\&conID=123\&IwYEAR=2009 $>$. Acesso em: 25 de fevereiro de 2010.

LADIK, D.; SOUZA, R. M. de. Cipozeiros em fase final de seu mapeamento situacional. Disponível em: <http://redepuxirao.blogspot.com/2010/02/cipozeirosem-fase-final-de seu.html>. Acesso em: 25 de fevereiro de 2010.

LEFF, E. Saber ambiental: sustentabilidade, racionalidade, complexidade, poder. Tradução de Lúcia Mathilde Endlich Orth. $3^{\underline{a}}$ ed. Petrópolis. Editora Vozes, 2004.

LÖWEN SAHR, C. L. Faxinalenses: Populações tradicionais no Bioma da Mata com Araucária. IN: 1ํ ENCONTRO DOS POVOS DOS FAXINAIS, 2005, Irati. Anais: Termo de referência. Irati: Rede Faxinal, 2005. Impresso, p. 53-62.

O Pré-Moderno na Pós-Modernidade: refletindo sobre as comunidades de Faxinais da Floresta com Araucária do Paraná. In: MARAFON, Gláucio José; RUA, João; RIBEIRO, Miguel Ângelo. Abordagens teórico-metodológicas em Geografia Agrária. Rio de Janeiro: Eduerg, 2007. p. 207-223.

. Os mundos faxinalenses da floresta com araucária do Paraná: racionalidades duais em comunidades tradicionais. Terr@ Plural, Ponta Grossa, 2 (2): 213-226, jul./dez., 2008.

; CUNHA, L. A. G. O significado social e ecológico dos Faxinais: Reflexões acerca de uma política agrária sustentável para a região da mata com araucária no Paraná. Emancipação, Ponta Grossa, 5 (1), p: 89-104, 2005.

MATOS, M. Quebradeiras de coco do Maranhã: lutas e conquistas. Disponível em: $<$ http://www.adital.com.br/site/noticia2.asp?lang=PT\&cod=15040 >. Acesso em 10 de agosto de 2009. 
MURRIETA, J. R.; RUEDA, R. P. (Editores). Reservas Extrativistas. Gland, Suíça e Cambridge; Reino Unido/UICN (Unión Mundial para La Naturaleza, 1995. 132 p.

NERONE, M. M. Terras de Plantar, Terras de Criar: Sistema Faxinal - Rebouças 1950-1997. 2000, 286 p. (Tese de Doutorado) - UNESP, SP, Assis, 2000.

NEVES, J. G. Ribeirinhos, desenvolvimento e a sustentabilidade possível. Rondônia, Universidade Federal de Rondônia, 2008. 08 p.

PAIVA, A. Brumas da História do Brasil: ciganos e escravos, a verdade. Disponível em <www.ciganosbrasil.com/novo/brumas $>$. Acesso em 5 de agosto de 2009.

Ciganos, Tziganos, Gitanos, Boêmios, Zíngaros... Que são eles? E porque não devemos discriminá-los. Disponível em: $<$ http://www.google.com.br/search?hl=ptBR\&q=livro+Brumas+da+hist\%C3\%B3ria+d o+Brasil+Ciganos+e+escravos\&btnG=Pesquisar\&meta $=>$. Acesso em 5 de agosto de 2009.

PARANÁ. DECRETO № 3446. Curitiba: Casa Civil do Governo do Estado do Paraná, 1997. Disponível em: <http://celepar7cta.pr.gov.br/SEEG/sumulas.nsf/fcc 19094358873db03256efc00601833/fa1887bf3d2ab76b03256e99006389e4?OpenDo cument>. Acesso em: 15 de junho de 2009.

PARANÁ. Secretaria de Estado da Educação. Diretrizes Curriculares da Educação do Campo. Paraná. 2006.

PORTO-GONÇALVES, C. W. Amazônia, Amazônias. São Paulo: Editora Contexto, 2001. $178 \mathrm{p}$.

SABOURIN, E. Estratégias coletivas e lógicas de construção das organizações de agricultores no Nordeste semi-árido. Antropolítica. Rio de Janeiro, UFF, no 9, p. 110, 2001.

SANTOS, N. Seringueiros da Amazônia: sobreviventes da fartura. 2002, 330 p. (Tese de Doutorado) - USP, SP, São Paulo, 2002.

SILVA, L. C. K. da. Tropeirismo. In: SCORTEGAGNA, Adalberto; REZENDE, Cláudio José; TRICHES, Rita Inocêncio. Paraná Espaço e Memória: Diversos olhares histórico-geográfico. Curitiba: Editora Bagozzi, 2005. p. 106-129.

SILVA, P. C. G. da. et al. Estudo de trajetórias de desenvolvimento local e da construção do espaço rural no Nordeste semi-árido. Agricultura familiar pesquisa, formação e desenvolvimento. Belém, v. 1, n. 2, p. 5-27, 2000.

VASCONCELOS, E. de. Sociologia Rural. Minas Gerais: Imprensa Universitária Universidade Federal de Viçosa, 1977. 288 p. 
VASCONCELLOS, $M$. de. Comunidades tradicionais. Disponível em: www.uff.br/obsjovem/mambo/index.php?option=com_content\&task=view\&id=348\&lte mid=5rcos de. Acesso em: 28 de Abril de 2009.

ZIMMERMANN, S. A política Nacional de desenvolvimento sustentável dos povos e comunidades tradicionais - entre conflitos e conquistas. Disponível em $<$ http://www.observatoriodoagronegocio.com.br/page41/page42/files/Bol $02409 \mathrm{SZ}$ .pdf.> Aceso em: 03 de junho de 2009.

(Recebido em 27.06.2011. Aceito em 26.03.2012) 